\title{
Pre-existent Training: Opportunities to Increase the Success Rate of ERP Systems Implementations for Sustainable Development Business
}

\author{
Vasile Paul Bresfelean \\ Department of IT Applied to Economics \\ Faculty of Economics and Business Administration \\ Babes-Bolyai University, Cluj-Napoca, Romania \\ E-mail: paul.bresfelean@econ.ubbcluj.ro \\ Moreno-Doru Res \\ Department of IT Applied to Economics \\ Avram Iancu University of Cluj-Napoca, Romania \\ E-mail: moreno.res.uai@gmail.com \\ Calin-Adrian Comes (Corresponding author) \\ Department of Financial- Accounting \\ Petru Maior University of Tirgu-Mures, Tirgu-Mures, Romania \\ E-mail: calin.comes@ea.upm.ro
}

Received: Sep. 10, 2015 Accepted: Sep. 23, 2015 Published: November 1, 2015

http://dx.doi.org/10.5296/jse.v5i4.8270 URL: http://dx.doi.org/10.5296/jse.v5i4.8270

\begin{abstract}
The method described in this article is the result of authors' own experience in implementing ERP systems in the process industry for sustainable development business. Founded on this means, authors wish to significantly raise the low success rate of ERP implementations, according to the research literature. The article encompasses an analysis of information systems' methodology for implementation, together with highlights of resource-intensive
\end{abstract}


areas and possible implementation failures. The novelty of our proposal is an initial module of pre-existent training (just before the system analysis phase in the project life cycle implementation) based on a standard model, the same model that was verified by the supplier, satisfying client requirements contained in the technical specifications manual. In the last part, there are presented the advantages and disadvantages in utilizing this method for the two ERP implicated parts: system provider and beneficiary.

Keywords: pre-existent training, implementation process, sustainable development business 


\section{Introduction}

Enterprise Resource Planning (ERP) implementations are complex processes (Holland \& Light, 1999), (Hack \& Berg, 2014), requiring an accord from the whole company to reengineer its heart business developments and make the most of the software. They have rapidly become the fundamentals for decision making progressions in many organizations, but also have often failed to deliver their expected benefits (Basu \& Lederer, 2011), (Ghosh, 2012), (Reş, 2011), (Xue, Liang, Boulton, \& Snyder, 2005), (Bresfelean, Bresfelean, Ghisoiu \& Comes, 2006), (Ward, Daniel, \& Peppard, 2008), (Subic, Shabani, Hedayati, \& Crossin, 2013). A new ERP solution is of crucial importance for a company's future (at least in the next decade of subsistence) due to its all-encompassing character (Holland \& Light, 1999): it automates core corporate activities (manufacturing, human resource, finance, supply chain management), incorporates top practices to assist rapid decision-making processes, cost diminution, and superior management control. The ERP integrated information systems are one of the key IT progresses, offering enormous benefits for companies and a standardized solution for the old legacy systems, while could be devastating in case of implementation failures. Its implementation has gradually grown in complexity, due to the nature of complex activities from all economical spectrum (Eckartz, Daneva, Wieringa, \& van Hillegersberg, 2009), therefore determining a combination of management and business transformations, together with a professional software configuration. In the late 90 's, studies showed that ERP implementations success rate was less than $40 \%$ and the great majority were behind schedule or exceeded the funds (Xue, Liang, Boulton, \& Snyder, 2005), (Ward, Daniel, \& Peppard, 2008), possibly due to poor cost and schedule estimations or changes in project scope rather than project management failure. Even in recent years (Eckartz, Daneva, Wieringa, \& van Hillegersberg, 2009), (Subic, Shabani, Hedayati, \& Crossin, 2013) after costly IT investments, numerous companies (65\% from a case study sample) complained about their business cases that failed to identify and manage benefits in the deployment processes. Furthermore, 70\% of ERP implementations proved to be unsuccessful (Al-Mashari, 2006) mainly due to (Eckartz, Daneva, Wieringa, \& van Hillegersberg, 2009): business strategies, project delays, cost overruns and underestimation of the effort required for winning managerial changes. Customer companies expect for its money to acquire systems that essentially work as planned and as advertised, while unfortunately ERP sellers sometimes prove to be unprepared to deal with clients' worries and business challenges that might appear in the implementation process. PCWorld magazine presented several top failures in ERP implementations (Hack \& Berg, 2014):

- UK government scrapped the $£ 12$ billion National program for IT in the National Health Service (NHS) - the electronic health records project for all citizens was a disappointment.

- New York City's CityTime project failed fairly as a result of alleged unlawful actions and its budget grew from $\$ 63$ million to $\$ 760$ million.

- Massive technology distributor Ingram Micro failed to implement SAP products in Australia, affecting its first-quarter profits, which dropped from \$70.3 million to $\$ 56.3$ million. 
- Montclair State University sued Oracle over a PeopleSoft project, while Oracle hit back, claiming it was the school's liability.

- Commercial outdoor furniture seller ParknPool sued Epicor to court, naming the implementation of its project a "big mess", due to failing to deliver a seven-week project that went off for seven months.

- The government of Marin County, California, sued Deloitte Consulting and SAP in federal court over allegations of a scheme that aimed at bilking the county out of more than \$20 million, in connection with a failed ERP project.

- Reports from an Idaho state auditor showed problems with a new system developed by Unisys for processing Medicaid that could lead to the loss of millions of dollars (etc.)

Starting from the rate value of ERP successful deployments, and based on the experience we gained on ERP implementation (such as Microsoft Dynamics NAV), we developed our particular implementation methodology for the integrated computer systems. ERP systems' deployment have long been the basis of our industrial and training practice, determining us to propose a novel module of pre-existent training (just before the system analysis phase in the project life cycle implementation) based on a standard model (Bresfelean, Bresfelean, Ghisoiu \& Comes, 2007).

\section{Literature review}

Sustainability is part of our strategy and all of its processes (von Rosing, Coloma, \& von Scheel, 2015) are related to Business Process Management (BPM). The Rio Earth Summits of 1992 and 2012, and the Kyoto Protocol (1997) with its roots in the Bruntland Commission report "Our Common Future" (WCED, 1987) defined sustainable development business as "development which meets the needs of current generations without compromising the ability of future generations to meet their own needs". Some studies measured the impact of business sustainability over financial performance (Eccles, loannou, \& Serafeim, 2012) others underlined the intensity of business sustainability in association with market-based performance indicators (Lee, Pati, \& Roh, 2011). Sustainable education games' approach to all disciplines could be a relevant metric for environment and business management (Kim, 2015) with the idea to defined and interpret versus redefined and reinterpret education like a powerful engine for sustainable business development (Van den Branden, 2015). The Sustainable Business Model at the organization level changes the structural and cultural capabilities (Stubbs \& Cocklin, 2008) on economic, environmental, social, holistic characteristics and attributes. Transformative Business Sustainability (TBS) in (Beverly \& Svensson, 2014) describes a methodology for managers to "plan, implement and assess practices to provide a holistic view of sustainable business activities that supports the development of a company and its network". TBS model represent a sustainability map for navigation between elements within and external to any organization involving complex interaction on: economic, environmental and social level. In (Tisak, 2015) the author presented a Business Model for Sustainability Commitment. Leadership in Energy and Environmental Design LEED was proposed by the United States Green Building Council 
(USGBC). LEED business model for sustainability represents a benchmark through which an organization can prove the compliance to defined sustainability goals for the design, construction, operation, and maintenance of green buildings, homes, and neighborhoods (Boeing, Church, Hubbard, Mickens, \& Rudis, 2014). The Environmental Information Technology (EIT) master plan presented in (Box, 2002) identified and prioritized information system improvements to increase environmental performance. The EIT covers the following components in a master plan: Environmental Monitoring Strategy, Data Acquisition Strategy, Data Storage Strategy, Sensor and Instrument Selection, Data Monitoring Strategy, Data Retrieving and Handling, Analytical Tools, Hardware, and Software. Green IT or ICT sustainability represent the empirical research and performed activity of environmentally sustainable computing. In (Murugesan, 2008) Green IT was defined like "designing, manufacturing, using, and disposing of computers, servers, and associated subsystems - such as monitors, printers, storage devices, and networking and communications systems efficiently and effectively with minimal or no impact on the environment". The mélange of IT resources and complementary human and management resources offer capabilities with competitive advantage (Bharadwaj, Bharadwaj, \& Bendoly, 2007) Product longevity represents maintaining the IT infrastructure to extend its life cycle, and the contribution to Green IT is to expand equipment's lifetime benchmarking with ecological footprint. Data centers are energy intensive from IT infrastructure to HVAC equipment solutions that combine the Aeolian and Solar energy and represent a chance to improve the energy efficiency (FEMP, 2015). Sustainable Information System (SIS) is an Information System who covers the following items: "adaptation to its environment, involves relevant stakeholders, and supports the knowledge lifecycle" (Maruster, Niels, \& Peters, 2008). The concept of Eco-Efficiency (Yadong, Dingjiang, Bing, \& Shanying, 2013) was extended to IT environment in order to measure the transformation from an unsustainable to a fully sustainable IT system (Trepant, Chow, \& Baker, 2015).

\section{Classical versus pre-existent training implementation methods}

At the time when top managers of a company take the decision to implement a new IT system to entirely replace the old ones, they most probably select an ERP integrated information system because it could fully shape the business flows of the company. First step in this long process after the ERP implementation decision until its completion is drawing up the Tender book. This document collects the requirements expressed by all compartments of the beneficiary company. It is important for these requirements to reflect the actual needs, to be clearly presented (explicit) and to include the referred processes as close to $100 \%$, so that the resulted document could be worthwhile. Failures in multiple ERP deployments were chiefly based on the inconsistencies of this Tender book. By analyzing the implementation process from the resources consumption point of view, as shown in Figure 1, we have found that the greatest value is recorded at the foundation of the pyramid, where basic requirements are described. 


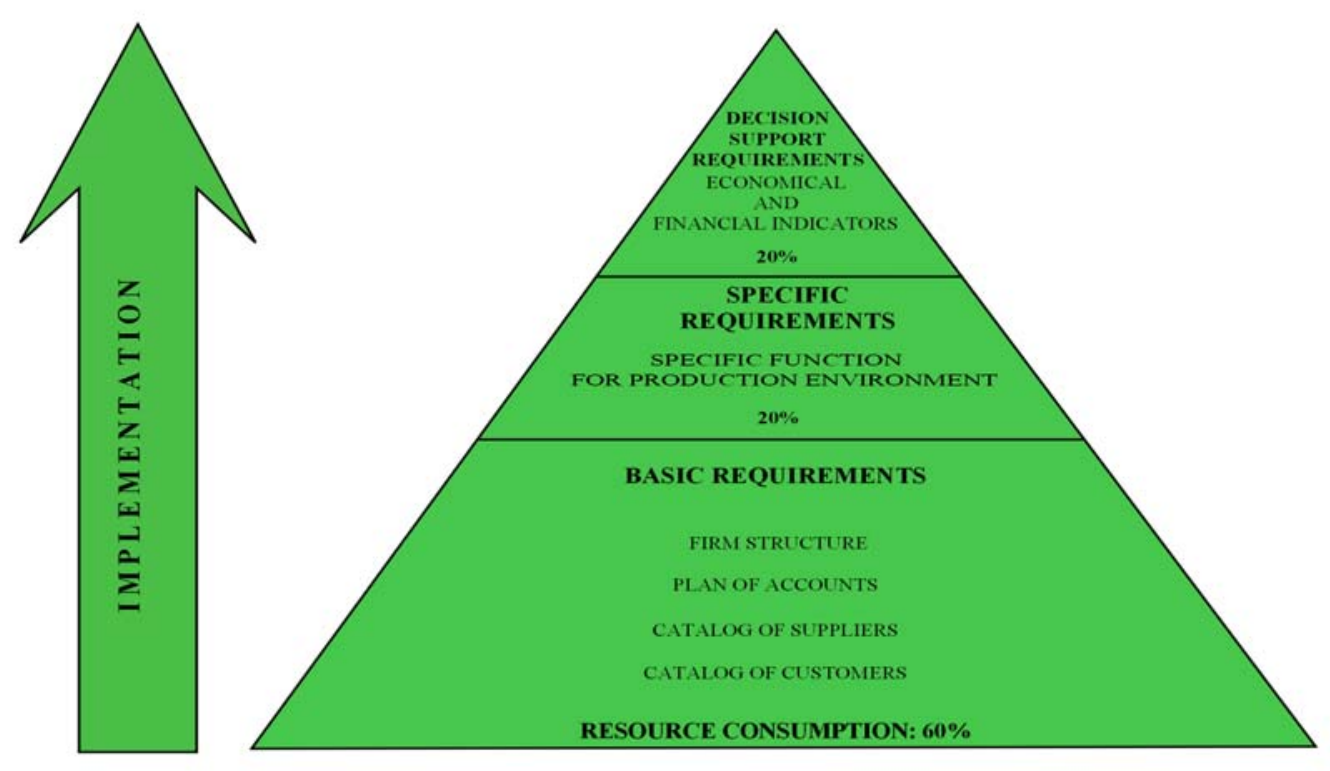

Figure 1. Resource consumption pyramid for an implementation process

Through resources we understand any consumption or effort directly related to the deployment process of sustainable development business, i.e. time, costs, personnel, logistics, raw materials, environment, and any combination of these factors involved in it.

Why is there such a high rate of failures in ERP deployments?

The answer to that we believe can be found in the compromises made by the two sides, one composed of experts in the new system (for the supplier) and other made of specialists in business requirements (for the customer). It can be seen from the statement above that we are not talking about a single deployment team, a mixed team supplier/customer, but two teams, each with a decision maker. They both have a common objective: the implementation success. Nevertheless, every team desire to rapidly reach it, with minimal costs and, unfortunately, with different tactical objectives:

- The supplier's team - has all the interest to implement the solution as close as possible to the standard model, because of easier scalability and post-deployment maintenance, on the same funds (as it is about the subscription system);

- The customer's team - has the interest to cover all of the requirements expressed in the tender book and, at all times, all the new requirements measured during the analysis phase, but these specialists, have minimum knowledge or none at all of new system's facilities, which is the subject of such implementation. 


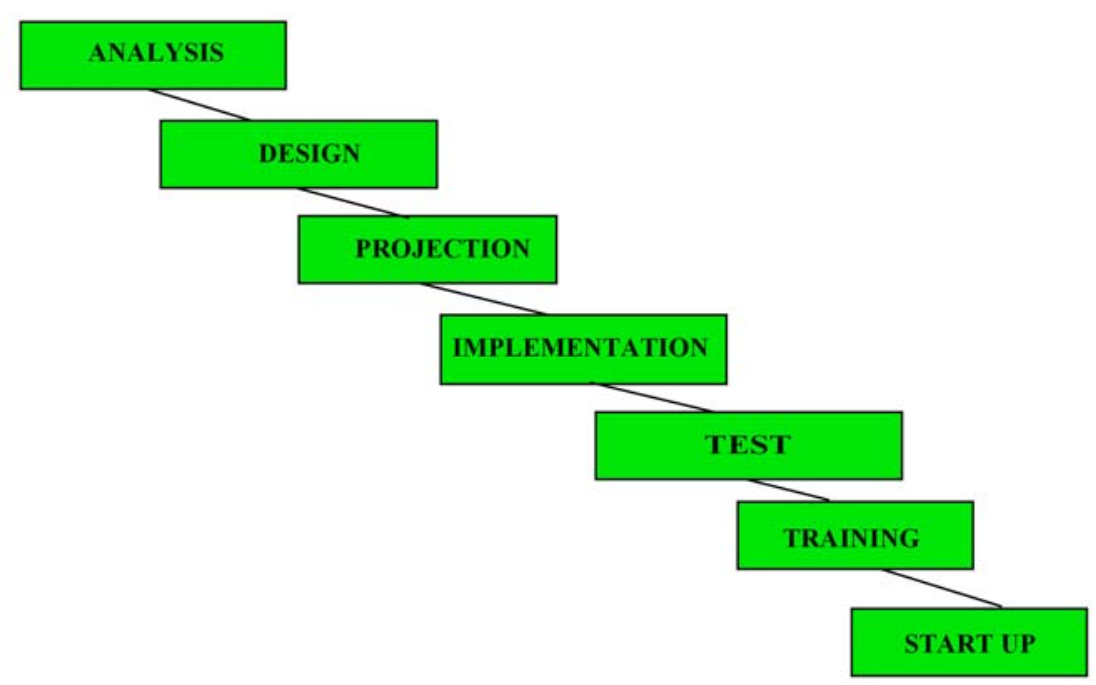

Figure 2. Classical implementation of an information system: based on (Reş, 2011 )

Due to the two specific interests, which eventually converge, there are certain implementation compromises, which generally mean the customer renounces to some of the requirements expressed when confronted to costly development alternatives. The compromises' dimension makes the difference between success and failure, but, as Figure 1 shows, the whole system is pyramidal and thus the concessions made could deteriorate the pyramid basis.

Starting from a point, from a certain percentage of compromises, the assembly might not last and at the end, the considerable effort made during deployment would have not met the strategic requirements expressed by managers. We strongly consider that, by using this method, the two teams engaged on the implementation efforts would constitute, right from the start, a single team with constituents very well aware of both customer requirements plus of the possibilities and limitation in the new system. In contrast to the classical implementation variant of an information system (Figure 2) we propose a new approach illustrated in Figure 3. 


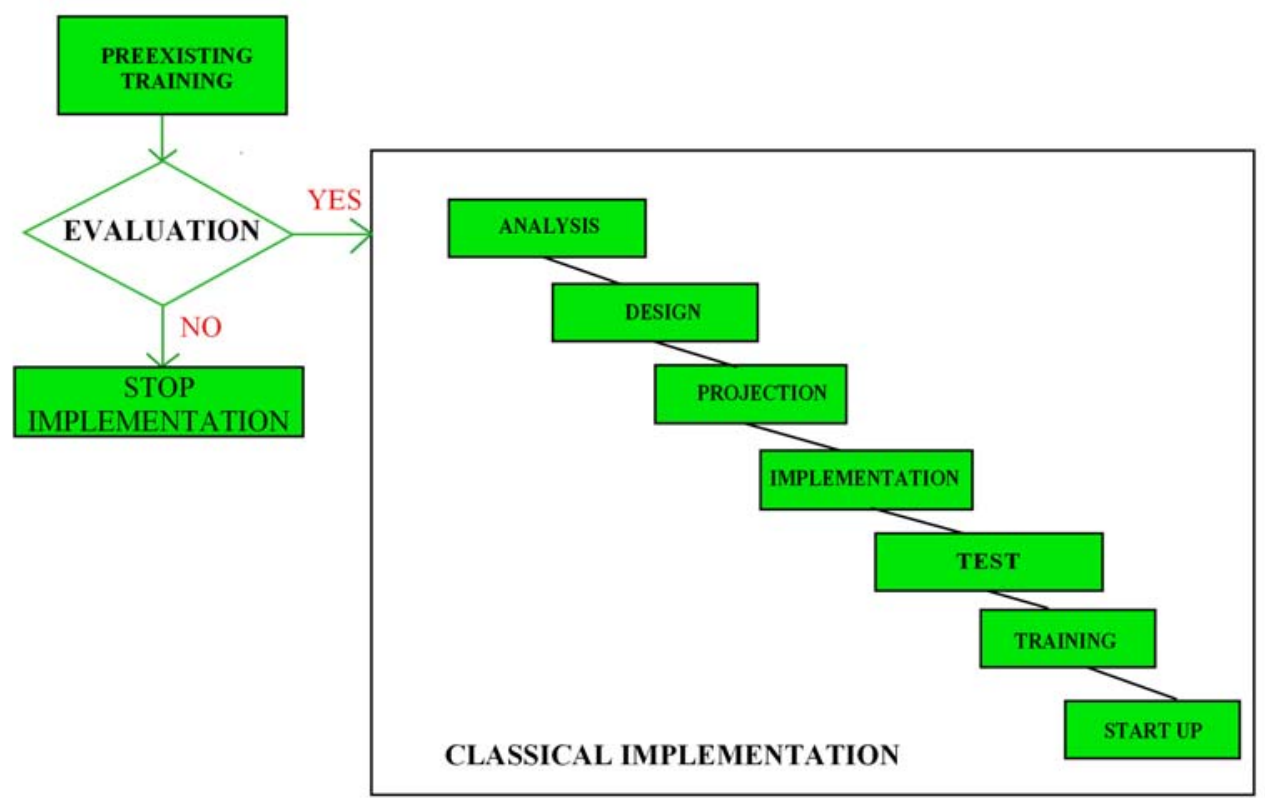

Figure 3. Pre-existent training implementation approach for sustainable development business

The proposed method has the role to initiate, just before the system analysis stage (part of the deployment project's life cycle) a module to compute intensive training on standardized modeling basis. Here are some of the features of the pre-existent training used in the implementation of an information system:

- After choosing the best suiting software solution (both in terms of requirements coverage in the tender book as well as implementation costs affordability) there will be specified in the potential supply contract a compulsory intensive training prior to the implementation process, via a standard model of the application.

- This model would be that particular solution used by the provider to test the degree of fulfillment of the beneficiary requirements enclosed in the tender book.

- The key in choosing that certain provider and its software as the implementation solution was the pledge that it could be able to totally or mostly cover the specifications.

Founded on our experience in ERP systems schooling and deployment, and with the purpose to increase that $40 \%$ success rate, we propose a method for the customer's team to test the system, prior to implementation: a team of specialists belonging to the beneficiary needs to know the new system thoroughly in order to test all its functions. Such performance could be reached only throughout a professional training conducted by the supplier. These are basically, the main motivations in suggesting a comprehensive training module in the pre-deployment phase; therefore, we can talk about two phases of training: 


\section{Macrothink

- Pre-existent training - the first step in changing the old legacy systems with a modern ERP system, which does not belong to the implementation phase, since it is based on a standard version of the ERP not yet customized for the beneficiary company.

- Final training - the last step in the implementation phase, when the complete standard and customized facilities of the ERP system are presented.

For the reasons shown above there is a need for a very good collaboration, a perfect symbiosis between the two teams, who must work as one for the major objective: a successful implementation. This training on the fully functional standard version offered by the supplier, obviously on a sample database, would most likely bring to light the logic of the new system and its possibilities.

\section{Pre-existent training approach for sustainable development business}

The main objective, towards which our proposed method aims, is for the new prospective clients / users to become familiar with the logic and the functions of the ERP system (in its standard version). By standard version we understand that certain system configuration on which the supplier tested all the customer's requirements found in the tender book. Based on that, the supplier saw its product as a feasible solution for the customer. At the end of this training period, future users must achieve an average comprehension in operating and administrating the new system. The two teams of specialists involved in the deployment will undergo a cohesion process so when the actual implementation begins, to be able to positively work as one squad, with a sole objective: the successful implementation for a sustainable business development.

\subsection{Features of sustainable development business success}

We consider that there are a number of fundamental requirements for attaining the most from the pre-existent training, namely:

- The participants in the training process should be the future key users in the customer company;

- The consultants (from the supplier company) for each module/field to be implemented should take the course lecturer roles;

- Training sessions should take place at the supplier's headquarters training center. Thus, the consultants could have all the necessary resources to demonstrate the new system's performance.

The proposed modes in which the training should take place are as follows:

- Establishing the composition of the 2 teams;

- Mutual sending/receiving of all members' resumes, which will ease the interpersonal communication and establish a trustworthy audience;

- $\quad$ Training Sessions 1-8. 
- Early evaluation of the effectiveness of this training will be completed by personnel appointed by the two top management structures in an enlarged joint session, which we labeled Session 9. The assessment will take into account the extent to which the standard solution already covers the tender book terms and also will estimate the dimension of further product developments to satisfy almost all customers' requirements. If the volume of developments exceeds $10 \%$ of existing functions, then we would suggest abandoning the implementation project of this software solution.

- Session 10 will have the purpose of official announcement of the evaluation result. In case of positive findings, the schedule of implementation would be established. In the other case, of an unfavorable response to the proposed standard solution, the two sides would make arrangements to discontinue their collaboration and certain compensations for the training expenses.

Table 1. Pre-existent training - sessions.

\begin{tabular}{|l|l|}
\hline \multicolumn{1}{|c|}{ Session 1 } & \\
\hline $\begin{array}{l}\text { Start of the training process through a product overview product meeting } \\
\text { Illustration of the degree in which the new system covers the customer's } \\
\text { specific requirements }\end{array}$ & $\begin{array}{l}\text { Entire } \\
\text { team }\end{array}$ \\
\hline \multicolumn{1}{|c|}{ Session 2 Session 3 } & $\begin{array}{l}\text { Entire } \\
\text { team }\end{array}$ \\
\hline \begin{tabular}{l} 
System architecture and main required settings. \\
\multicolumn{1}{|c|}{ Session 4}
\end{tabular} & $\begin{array}{l}\text { Entire } \\
\text { team }\end{array}$ \\
\hline $\begin{array}{l}\text { Practical examples of record inputting in the system, and the main generated } \\
\text { reports - entire team participation. }\end{array}$ & $\begin{array}{l}\text { Entire } \\
\text { team }\end{array}$ \\
\hline $\begin{array}{l}\text { Practical examples on retrieving the inputted data. } \\
\text { Filtering tables, building complex filters, sorting results view sites, screens } \\
\text { customization, etcetera. }\end{array}$ & $\begin{array}{l}\text { Entire } \\
\text { team }\end{array}$ \\
\hline $\begin{array}{l}\text { Continuing or repeating the data retrieval approach. } \\
\text { Sessions } 4 \text { and } 5 \text { are crucial in "winning" customer confidence in the } \\
\text { supremacy and possibilities of the new product. }\end{array}$ & $\begin{array}{l}\text { Wession } 6 \\
\text { in pairs }\end{array}$ \\
\hline \begin{tabular}{l} 
New system functionality presented on each module. \\
Pair working on separate modules: consultant - key user allocated that way. \\
focused on how the solution meets the Tender book requirements for that \\
module; \\
\hline \\
$\begin{array}{l}\text { Each key user fill in a questionnaire for his/hers domain (defined by the } \\
\text { that module }\end{array}$
\end{tabular} & Per user \\
\hline
\end{tabular}




\begin{tabular}{|c|c|}
\hline Session 8 & \\
\hline Present the results of the survey to the team. & Entire \\
\hline Q\&A / practical demonstrations to clarify any misunderstandings. & Team \\
\hline At the end of the session, the consultants (from the supplier company) write & $\&$ \\
\hline their own comments on the surveys, sign them as acknowledgement of the & Per \\
\hline client's staff point of view. & consultant \\
\hline \multicolumn{2}{|l|}{ Session 9} \\
\hline $\begin{array}{l}\text { Enlarged joint session for an early evaluation of this training - done by } \\
\text { personnel appointed by the two top management structures. }\end{array}$ & $\begin{array}{c}\text { Other } \\
\text { personnel }\end{array}$ \\
\hline \multicolumn{2}{|l|}{ Session 10} \\
\hline Official announcement of the evaluation result. & $\begin{array}{c}\text { Entire } \\
\text { Team \& } \\
\text { Top } \\
\text { managers }\end{array}$ \\
\hline
\end{tabular}

The ten sessions were not established by chance. They cover two weeks of actual working days which could be considered sufficient to a thorough analysis of the standard solution. Actual time consumed for each meeting is to be determined at training inauguration and could be over fulfilled in certain days, by mutual agreement, so that to arrive at a more complete result. In an affirmative scenario to continue the implementation, the effort and time spent with pre-existent training would be unquestionably compensated by a significant reduction of the final training period.

\section{Advantages and disadvantages of pre-existent training}

Some of the advantages and disadvantages for the two involved parties, customer and provider, can be described as following:

Client - advantages

- Key users ("key user") will be familiar with the logic of the new system and will be motivated to be trainers for other colleagues who did not partake in implementation,

- Will become familiar with data entry screens and extraction results, with existing information filtering methods, thus gaining confidence in the possibilities of the new system,

- Will have to face an "A to Z" functional model, i.e. the settings to statistical reports,

- Will get acquainted with the "know-how" brought by the new solution,

- Will be able to complete the series of questions asked in previous presentations, during the session of viewing various solutions,

- Will establish interactions with the supplier's team of consultants, in a lower stress climate instead of training under real operational pressure in the new system, and working in the legacy one at the same time.

- Will be able to detect any possible gap sites or areas where development is needed, 
- In extreme cases, it may be noticed from the start that the solution chosen does not match the requirements and the customer can thus terminate the contract before the implementation wave is launched with copious expenses.

Client - disadvantages

- Establishing a team of key users from staff who actually work with the new software solution without the ones not directly involved in the systems maintenance system nor the beneficiaries of synthetic situations (e.g. Heads of departments),

- Transfer of implementation decisions from top managers to actual users. The risk is understandable in terms of an opposition / resistance versus the solution itself or towards the act of changing the system,

- A need to allocate sufficient time for key users to participate in the standard model coverage, which would be rather placed outside the customer location, so that the user could be detached from current tasks and pressure,

- A sustained intellectual effort to assimilate new concepts encapsulated in the proposed solution, and in a reasonably short time. In order to facilitate this matter we propose a multiple-choice test at the end of that early training period in order to reveal for each modules / users the degree of awareness. Based on the reported results, the customer company may start up the analysis activity or may possibly recommence certain presentations / modules.

Supplier - advantages

- Full support from the beneficiary, without hesitation, after implementation start,

- A knowingly united and motivated team available for deployment,

- A fast implementation cadence, since many misunderstandings could be cleared in the pre-existent training,

- Development offerings, arisen from the analysis, could be more easily accepted by the beneficiary.

Supplier - disadvantages

- The need for a standard model of the IT solution to be closer to client's activity, in order to ease key users' effort to extrapolate their views and how the final solution will be like,

- Keeping unchanged the team of consultants throughout the implementation with the aim of not losing the human connections gained in pre-existent training,

- Accepting the risk of an abrupt and politely end of the contract, when the customer considers the solution needs further development (customizations) of more than $10 \%$ over its standard features (to be executed by the supplier).

Why coming up with this particular method? Due to the fact that during ERP implementations we observed that many of the functions of the know-how were ignored by 
the key users due to:

- Stress, as they were working in parallel in the two systems (new and legacy),

- They mostly focused on identifying functions or features that best resembled the old system (which certainly offered them a feeling of stability),

- The ERP version for implementation did not have all the necessary settings, which had to be made during the deployment.

These aspects were confirmed by the supplier's consultants, who also noted in previous implementations, for other firms, the same phenomenon of superficiality in dealing with a novel purchased system. Also, we must acknowledge that supplier firms are interested in making additional developments by demand, within a profitability level, whose cost may possibly exceed the cost of purchased licenses. We underline the fact that the pre-existent training does not mean giving up the usual training module made after the design phase, based on a personified instruction model for the client company. During the implementation process we believe that key users should not be asked to issue verdicts before really knowing the new system. This can lead to a complete list with many gaps and possible progress. It is obvious that the supplier company is an advantage because they support their own development team and thus increase proceeds. Unluckily, the key users' reward to "force" the ERP system to resemble the legacy system cannot be the measure of their efforts. Why do we consider this? Because many of the standard validations (constraints) are lost throughout the changes in system's functionality. These validations generally ensure that the system shall not circulate inconsistent data. In addition, by asking a thorough modules redesign, even by bringing in the argument of "country-specific legal requirements", some modern methods of economic analysis and functions may be omitted from implementing. This can be solved, as argued before, through a consistent training on an ERP standard version before the analysis phase. If end users learned to set up the system and to use it like many other employees of worldwide companies, those developments would not be necessary (which frequently differ only from the angle in which the problem is seen). If end users were confident about the new system, then they would have to request the decision makers to accept the new forms of approach and presentation for the business processes and their results reporting. Possible pre-existent training achievements are also needed in the actual implementation and testing phases, where users work on multiple levels, for example:

- A pure technical one - server installation,

- Creating the Production main database,

- Verification of the requirements expressed in the gap sites,

- Modules validation etc.

The testing activity is usually more time and resources consuming, as it is done by a parallel inputting of all documents from certain months, in order to compare the records integrity with the legacy system. In this process, only key users execute the main tasks, namely staff that do not perform their daily executive operations but coordination tasks. As a result, they are 
required to train their subordinates, thus doubling their work because "the company life" goes on: documents are recorded in the old system in parallel with the new ERP system (obviously more time consuming, since everything is quite new).

In addition, the last phase (Startup) begins with a definitive migration of balances, users and users rights assigned in the ERP system. During the first weeks from the actual launch, system blockages could emerge mainly due to improper settings of user rights and roles but also due to their lack of knowledge of the concurrent users' environment. Founded on a brief training, all users could easily avoid these blockages and thus the new system could be advisedly used.

\section{Limitations and future research}

The proposed research is limited to evaluating an ERP system from a single supplier to 27 companies from Romania where authors perform the functions of: users, key users, junior consultants, senior consultants, or managers of integrated ERP system implementation in the field: pharmaceutical, chemical fertilizer production, production consumer goods and automotive. In future we intend to analyze a large number of ERP implementations from different vendors that play an important role in the economy of Romania.

\section{Conclusions}

Our approach of sustainable development business projected method brings a faster pace of implementation in terms of increased confidence in the new product. The novelty of proposed method is essentially to familiarize prospective users with the logic and functions of the newly integrated system. When we filter these advantages, we consider that perseverance on the ways to retrieve the information entered in the new system is a fundamental element, which brings in trust for the new users.

Furthermore, knowing the possibilities for views and modules customization, queries and filters results and so forth, certainly adds a positive comfort during the implementation process. At the same time, any decision to abandon the product implementation could be thoroughly justified, thus saving significant expenditures. In this case, the conclusions drawn after pre-existent training would help prepare a more accurate tender book, or, if this was not the quandary, these findings would more rigorously assist in selecting the desired solution. Notwithstanding which of the two alternatives happens, we regard it as an achievement.

\section{Acknowledgments}

This paper is made and published under the aegis of the Research Institute for Quality of Life, Romanian Academy as a part of programme co-funded by the European Union within the Operational Sectorial Programme for Human Resources Development through the project for Pluri and interdisciplinary in doctoral and post-doctoral programmes Project Code: POSDRU/159/1.5/S/141086.

\section{References}

Al-Mashari, M. (2006). Enterprise Resource Planning (ERP) Implementation: a Useful Road 
Map. Int. J. Management and Enterprise Development, 3(1/2), 169-180. http://dx.doi.org/10.1504/IJMED.2006.008248

Basu, V., \& Lederer, A. (2011). Agency theory and consultant management in enterprise resource planning systems implementation. SIGMIS Database, 42(3), 10-33. http://dx.doi.org/10.1145/2038056.2038058

Beverly, W., \& Svensson, G. (2014, 340-367). A framework to navigate sustainability in business networks: The transformative business sustainability (TBS) model. European Business Review, 26(4 ). http://dx.doi.org/10.1108/EBR-12-2013-0146

Bharadwaj, S., Bharadwaj, A., \& Bendoly , E. (2007). The performance effects of complementarities between information systems, marketing, manufacturing, and supply chain $\begin{array}{llll}\text { processes. Information } \quad \text { Systems } & \text { Research, }\end{array}$ http://dx.doi.org/10.1287/isre.1070.0148

Boeing, G., Church, D., Hubbard, H., Mickens, J., \& Rudis, L. (2014). LEED-ND and Livability Revisited. Berkeley Planning Journal, 27(1), 31-55.

Box, W. (2002). Sustainability is IT. Pollution Engineering, 34(1), 13-17.

Bresfelean, V. P., M. Bresfelean, N. Ghisoiu, \& C.-A. Comes. (2006) Continuing Education in a Future EU Member. Analysis and Correlations using Clustering Techniques. WSEAS TRANSACTIONS ON ADVANCES IN ENGINEERING EDUCATION 3, no. 11, 1016.

Bresfelean, V. P., M. Bresfelean, N. Ghisoiu, \& C.-A. Comes. (2007) Data Mining Clustering Techniques in Academia. In ICEIS (2), pp. 407-410.

Eccles, R., loannou, 1., \& Serafeim, G. (2012, March). The lmpact of a Corporate Culture of Sustainability on Corporate Behavior and Performance. National Bureau of Economic Research Working Paper Series.

Eckartz, S., Daneva, M., Wieringa, R., \& van Hillegersberg, J. (2009). Cross-organizational ERP management: how to create a successful business case? Proceedings of the 2009 ACM $\begin{array}{llll}\text { symposium on Applied Computing (SAC '09), 1599-1604 } & \end{array}$ http://dx.doi.org/10.1145/1529282.1529641

FEMP. (2015, August 21). FEDERAL ENERGY MANAGEMENT PROGRAM. Retrieved from Best Practices Guide for Energy-Efficient Data Center Design: http://www1.eere.energy.gov/femp/pdfs/eedatacenterbestpractices.pdf

Ghosh, R. (2012). A Comprehensive Study on ERP Failures Stressing on Reluctance to Change as a Cause of Failure. Journal of Marketing and Management, 3 (1), 123-134.

Hack, S., \& Berg, C. (2014). The Potential of IT for Corporate Sustainability. Sustainability, 6, 4163-4180. http://dx.doi.org/10.3390/su6074163

Holland, C., \& Light, B. (1999). A critical success factors model for ERP implementation. Software, Vol.16(No.3, ), 30-36. http://dx.doi.org/10.1109/52.765784

Kim, S. (2015). Interdisciplinary Approaches and Methods for Sustainable Transformation and Innovation. Sustainability, 7, 3977-3983. http://dx.doi.org/10.3390/su7043977 
Lee, J., Pati, N., \& Roh, J. (2011, January). Relationship between Corporate Sustainability and Tangible Business Performance: Evidence from Oil and Gas Industries. International Journal of Business Insights and Transformation, 3(3), 72-82.

Maruster, L., Niels, F. R., \& Peters, K. (2008). Sustainable information systems: a knowledge perspective. Journal of Systems and Information Technology, 10 (3), 218-231. http://dx.doi.org/10.1108/13287260810916925

Murugesan, S. (2008). Harnessing Green IT: Principles and Practices. IEEE IT Professional, 24-33. http://dx.doi.org/10.1109/MITP.2008.10

Reş, M. (2011 ). Integrated information systems. Cluj-Napoca, Romania: Risoprint .

Stubbs, W., \& Cocklin, C. (2008). Conceptualizing a "Sustainability Business Model". Organization \& Environment, 21(2 ), 103-127. http://dx.doi.org/10.1177/1086026608318042

Subic, A., Shabani, B., Hedayati, M., \& Crossin, E. (2013). Performance Analysis of the Capability Assessment Tool for Sustainable Manufacturing. Sustainability, 5, 3543-3561. http://dx.doi.org/10.3390/su5083543

Tisak, D. (2015). LEED as a Business Model of Sustainability Commitment. Strategic Planning for Energy and the Environment, 34(4). http://dx.doi.org/10.1080/10485236.2015.11415542

Trepant, H., Chow, G., \& Baker, E. H. (2015, September 8). The Eco IT Solution. Retrieved from Strategy + Business: http://www.strategy-business.com/article/08412?gko=88923

Van den Branden, K. (2015). Sustainable Education: Exploiting Students' Energy for Learning as a Renewable Resource. Sustainability, 7, 5471-5487. http://dx.doi.org/10.3390/su7055471

von Rosing, G., Coloma, D., \& von Scheel, H. (2015). Sustainability Oriented Process Modeling. In M. von Rosing, A.-W. Scheer, \& H. von Scheel, The Complete Business Process Handbook (pp. 493-510). Boston: Morgan Kaufmann. http://dx.doi.org/10.1016/B978-0-12-799959-3.00024-0

Ward, J., Daniel, E., \& Peppard, J. (2008). Building Better Business Cases for IT Investments. MIS Quarterly Executive, 7(1 ), 1-15.

WCED. (1987). World Commission on Environment and Development, Our Common Future. Oxford: Oxford University Press.

Xue, Y., Liang, H., Boulton, W., \& Snyder, C. (2005). ERP implementation failures in China: Case studies with implications for ERP vendors. Int. J. Production Economics, 97, 279-295 . http://dx.doi.org/http://dx.doi.org/10.1016/j.ijpe.2004.07.008

Yadong, Y., Dingjiang, C., Bing, Z., \& Shanying, H. (2013). Eco-efficiency trends in China, 1978-2010:decoupling environmental pressure from economic growth. Ecological Indicators, 24 , 177-184. http://dx.doi.org/10.1016/j.ecolind.2012.06.007 